\title{
Homeopathic Dilution Unit
}

National Cancer Institute

\section{Source}

National Cancer Institute. Homeopathic Dilution Unit. NCI Thesaurus. Code C48498.

A dosing unit that is based on homeopathic dilution. 